\title{
Fast changes of the solar irradiance
}

\author{
Teolan Tomson and Maire Hansen \\ Tallinn University of Technology, Ehitajate tee 5, 19086 Tallinn, Estonia; teolan@staff.ttu.ee \\ Received 5 May 2009, in revised form 13 August 2009
}

\begin{abstract}
The results of special measurements of solar irradiance with high resolution in time domain are compared with results of traditional measurements. Three possible characteristic parameters are studied to describe the dynamic quality of the recorded dataset: standard deviation, frequency density distribution law of increments and the number of fronts of the solar radiation per time unit. Recording traditionally one-minute average values of the solar irradiance, most of the changes cannot be registered in the condition of clouds cumulus humilis.
\end{abstract}

Key words: solar irradiance, standard deviation, increments, cumulus humilis.

\section{INTRODUCTION}

In the Northern Europe, due to prevailing and frequent Atlantic cyclones, solar radiation has an alternating nature. For solar PV-modules and farms forming a grid, fast changes of the generating capacity makes problems as the grid can perform in the conditions of balanced generated and consumed energy. Measurements made at the Tallinn University of Technology [ $\left.{ }^{1}\right]$ with high resolution $(1 \mathrm{~s})$ show the possibility of very high increments (the recorded absolute maximum was $705 \mathrm{~W} \mathrm{~m}^{-2} \mathrm{~s}^{-1}$ ) of the generated energy. These measurements in the summer season 2008 were an exception as regular measurements in the Baseline Surface Radiation Network (BSRN) are made with the sampling interval of $6 \mathrm{~s}$ and registered as one-minute average values. Naturally, recorded data with a sampling period of one minute cannot present processes in the second range, but we can use another approach and investigate how much information we probably loose using data with the one-minute sampling period. Although mostly scientific analysis of solar irradiance is based on hourly, daily or monthly averaged values of irradiance, often also one-minute averaged data has been used $\left.{ }^{2-6}\right]$. The aim of this study is to estimate the amount of lost dynamic information in the conditions of fast-changing irradiance. 


\section{THE METHOD}

We shall analyse the dataset with high resolution "as it is" and its sparser modifications, and compare the results in the scope of the characteristics, describing the dynamic behaviour of the irradiance. The dynamic quality of the irradiance can be evaluated by the value of (moving) standard deviation, by the distribution law of the increments and number of characteristic events per time interval. Increment $\Delta G$ of the solar irradiance $G(t)$ is defined as the difference of its two sequential values

$$
\Delta G=G(n)-G(n-1) .
$$

Characteristic event may be a local maximum (minimum) or any other event, which can be clearly defined. We use in this meaning a positive front, which is defined as the time instant when the instant value of the irradiance $G(t)$ will intercrosses its moving average value $\mu G(t)$.

\section{USED DATASETS}

Used datasets were recorded by the help of an automatic sensor, designed to detect only fast-changing irradiance $\left[{ }^{1}\right]$. In marine conditions of Tallinn $\left(59^{\circ} 23^{\prime} \mathrm{N}, 24^{\circ} 40^{\prime} \mathrm{E}\right) 18 \%$ of summer days have shorter or longer fast moving cloud formations cumulus humilis. If sensor discovers such an event, recording with high resolution started and continued up to the end of the fast alternating radiation. During the four summer months (from May to August) 2008 the automatic recording of the global irradiance produced 186 files (534 582 sampled data). In the analysis below we use fragments of two longest recordings in the files <080629_0955_1s> (14 484 data) and <080821_1359_1s> (19 530 data). These file names can be detected as "Y, M, D_time of the start_sampling interval". The last file is shown in Fig. 1 in its full length to demonstrate the changing structure of the irradiance during the whole recording. As files are too long to observe them well (too dense diagrams), we will present for the illustration only fragments of them, while analysis was made for the whole recording. Figure 2 shows the natural recording of the irradiance "as it is". Figure 3 shows the same recorded interval plotted from the sparser ("prefabricated") dataset.

Line "inst" uses every 60th instant value, but line "ave" uses averaged values for each preceding minute. We can see that both diagrams differ from the natural one (Fig. 2) while the difference is bigger for the line "ave". That is the first argument to confirm that averaged values present dynamic processes insufficiently. 


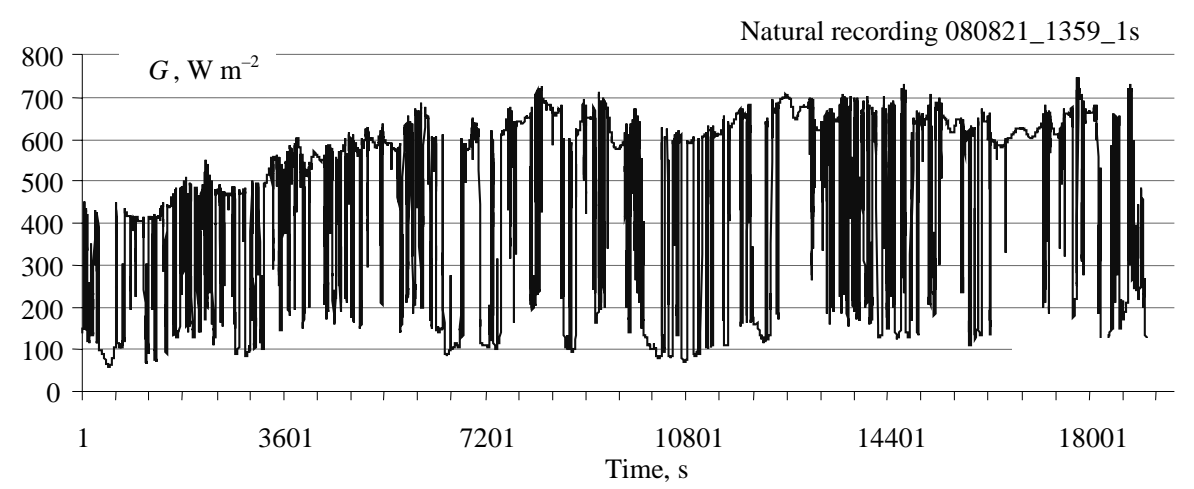

Fig. 1. Diagram of the solar irradiance with high resolution of recording.

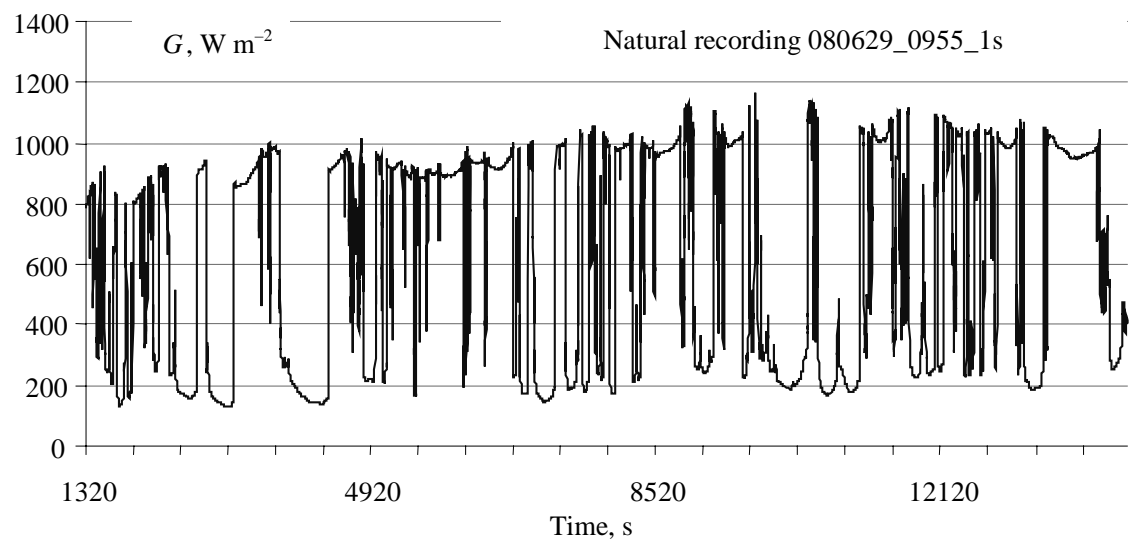

Fig. 2. Fragment of the diagram of the solar irradiance with high resolution of recording.

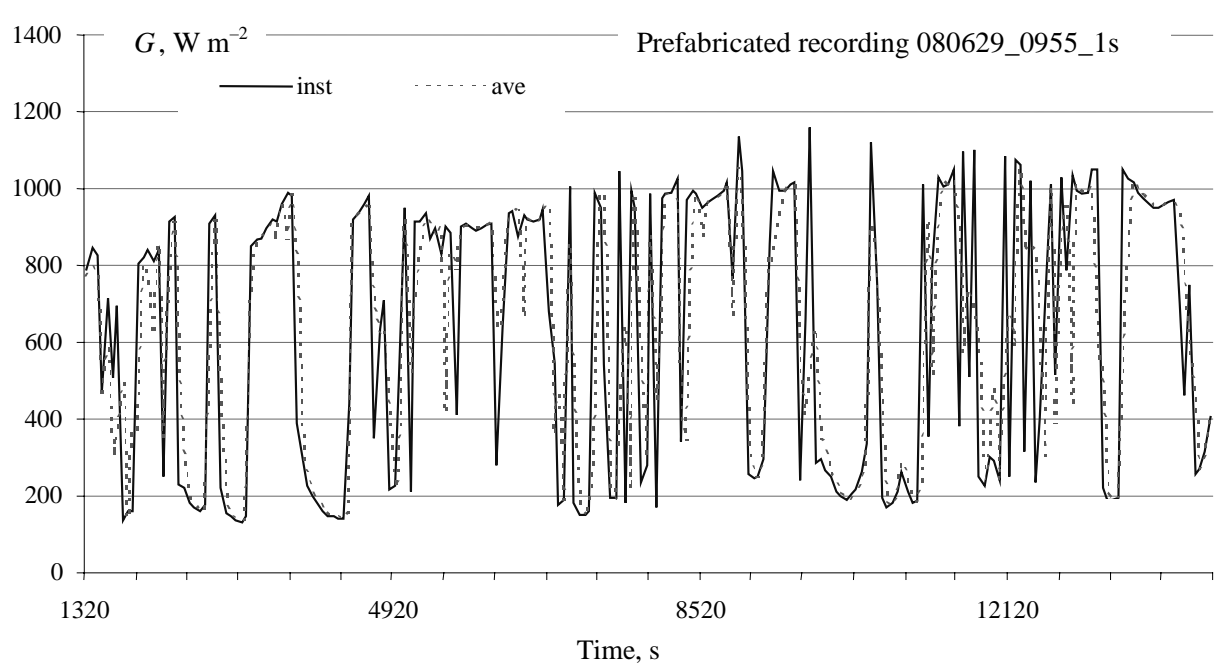

Fig. 3. Fragment of the diagram of the solar irradiance with sparser resolution of recording. 


\section{STABILITY OF THE FAST ALTERNATING IRRADIANCE}

Recorded solar irradiance under a cloud formation cumulus humilis is a pure stationary stochastic process as it is or after elimination of the trend due to the changing altitude of the sun. It means that its moving average and moving standard deviation remain constant along the whole process (19 $440 \mathrm{~s}$ in Fig. 1 or $12240 \mathrm{~s}$ in Fig. 2), what is a classical definition of stationarity. However, structures of their fragments are different in the time domain, containing more or less frequently alternating irradiance. In this meaning we can talk about the stability or instability of the stochastic process and to evaluate it by calculating autocorrelation functions (ACF) for certain time intervals (e.g. $1 \mathrm{~h}$ ) moving along the process. Calculated ACFs for the example in Fig. 1 are shown in Fig. 4. The bold line $r(3)$ is calculated for three hours long interval. Dashed lines are ACFs calculated for one hour long fragments inside this three hours long time interval in such a way that every new one hour long data series is selected half an hour later. It means that diagram $r(+1)$ is delayed for $30 \mathrm{~min}$ relative to the diagram $r(+0.5)$; diagram $r(+1.5)$ is delayed for $30 \mathrm{~min}$ in relation to the diagram $r(+1)$, etc.

We can see that the stability of fast alternating irradiance is low as the particular correlation intervals differ up to four times during the recording. The range of different correlation intervals is marked by $\{\tau\}$. While dynamic parameters, found out at different sampling conditions, may be sensitive to the structure of the irradiance, then it is expedient to control the behaviour of the standard deviation along the recorded dataset using a 22.5 min long moving window.

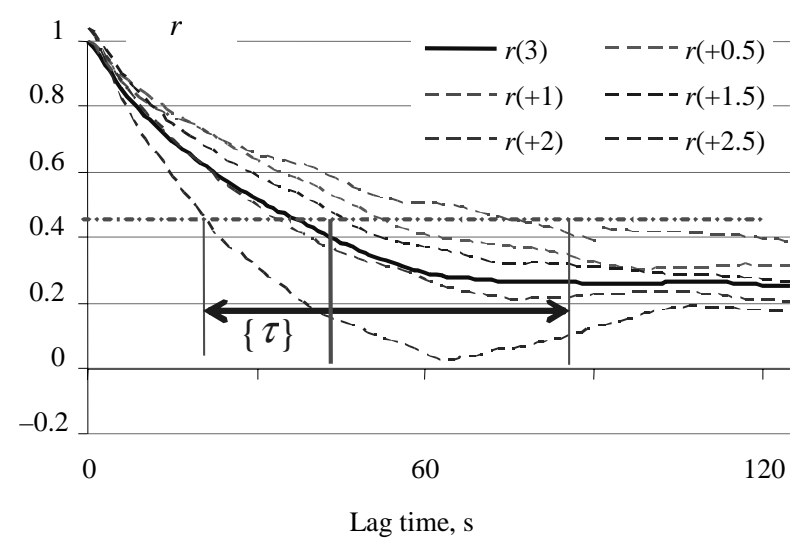

Fig. 4. Autocorrelation functions for the example in Fig. 1. 


\section{STANDARD DEVIATION}

Solid line "nat dev" is calculated using the natural recording with sampling interval $1 \mathrm{~s} \mathrm{(Fig.} \mathrm{5).} \mathrm{The} \mathrm{dashed} \mathrm{line} \mathrm{"inst} \mathrm{dev"} \mathrm{uses} \mathrm{each} \mathrm{60-th} \mathrm{recorded} \mathrm{data} \mathrm{and}$ the bold line "ave dev" uses averaged values of the irradiance for the moving $60 \mathrm{~s}$ long window.

We can see that sparser instant values do not much deform the diagram "inst dev" compared to the diagram "nat dev". Usage of averaged values (strategy of the BSRN network) involves significantly reduced value of the standard deviation and cannot be recommended. No clear dependence of the (moving value) of the standard deviation on the structure of irradiance cannot be detected (what was to be expected): relative value of the line "ave dev" is independent of the structure of recording (Fig. 2).

\section{INCREMENTS}

Increments are not very informative parameters for describing dynamic properties of the solar radiation. One single value of the increment does not characterize the recording; the frequency distribution function is required. This function shows the probability of increments with a certain value. Coinciding probabilities can be used to calculate total probability while several PV farms are connected in parallel to perform in the grid. In such a way considering increments is important. Considering equal frequency of positive and negative increments $\left[{ }^{4}\right]$ it is enough to investigate absolute values of increments. In Fig. 6 we consider only big increments for the examples shown in Figs. 1 and 2, which

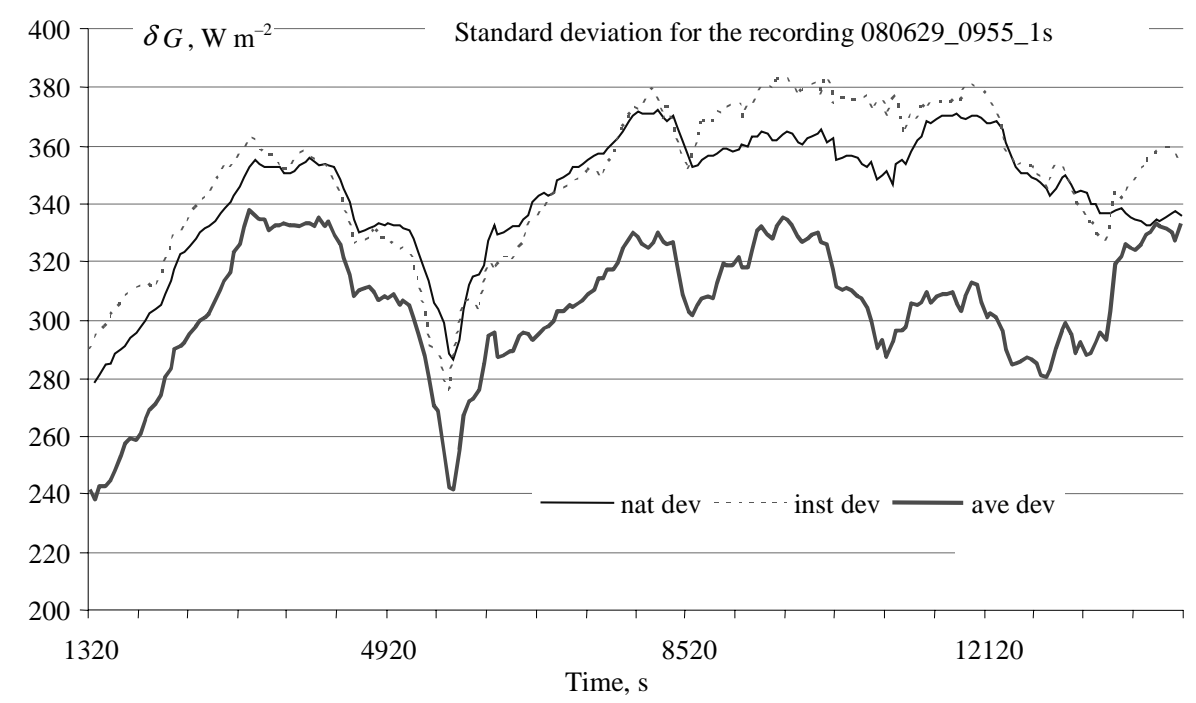

Fig. 5. Standard deviation of the irradiance with natural and sparser resolution of recording. 


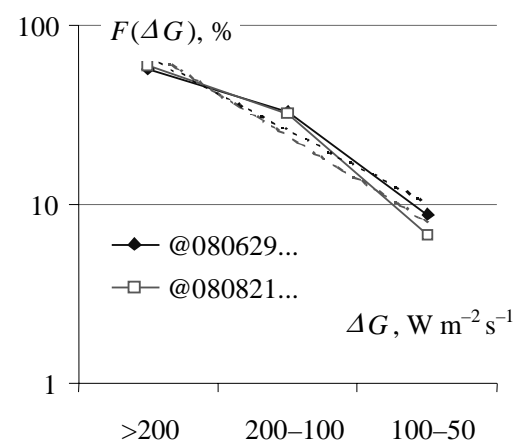

Fig. 6. The frequency distribution function of the absolute value of increments.

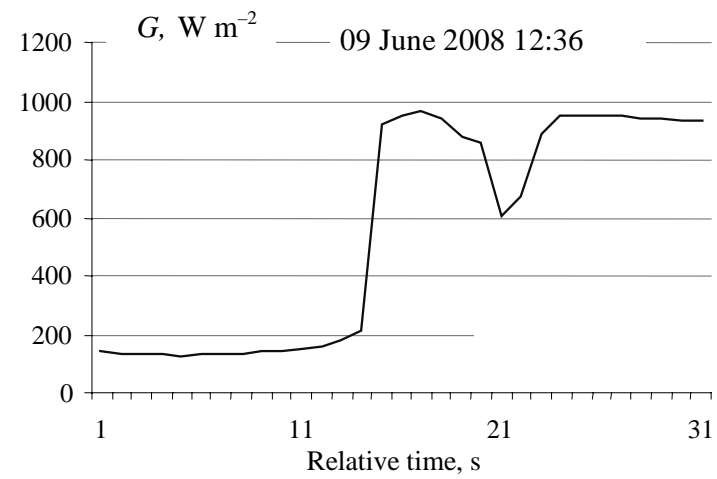

Fig. 7. The largest increment, recorded during the summer season 2008.

may influence the performance of the grid. Small increments $\Delta G<50 \mathrm{~W} \mathrm{~m}^{-2} \mathrm{~s}^{-1}$ are considered as fluctuations of the irradiance, which exist always due to the instability of clouds or turbidity.

Figure 6 is created for $1 \mathrm{~s}$ increments and it shows the frequency distribution law $F(\Delta G)$ practically equal to the exponential one (dashed lines). The same law is valid for 1 min increments $\left[{ }^{4}\right]$, but we have to mark that these functional dependencies cannot be compared since the time bases are different. Using $1 \mathrm{~min}$ sampling intervals we cannot say anything about $1 \mathrm{~s}$ increments. The largest increment found in the summer season was $705 \mathrm{~W} \mathrm{~m}^{-2} \mathrm{~s}^{-1}$ (Fig. 7), but fortunately it is an exception and most of (very) big increments exist in the range of $300-400 \mathrm{~W} \mathrm{~m}^{-2} \mathrm{~s}^{-1}$. Such increments involve stepwise changes of the generated PV power in the range of $30 \%-40 \%$ of the latter.

\section{FRONTS OF THE IRRADIANCE}

One possible parameter, showing dynamical properties of the alternating irradiance, is the number of its fronts per unit of time (or during the whole process). It is a single number, which is suitable regardless of the sampling interval. It allows comparing the amount of (specific) information, which we lose using sparser data. Definition of a front was presented above explaining the approach. Figure 8 shows the number of fronts, found out from the $4.9 \mathrm{~h}$ long fragment of the example in Fig. 1. The dashed line is the logarithmic approximation of the functional dependence.

Assessing the fronts, the sampling interval was varied. In such a way we can see the logarithmic dependence of the number of fronts on the sampling interval. Using the minute-long sampling interval we will lose most of the information in the case of cumulus humilis (57 vs 275 positive fronts). Comparison of the oneminute sampling interval for the usage of instant and average values shows that in the last case we will lose additional information (52 vs 57 positive fronts). 


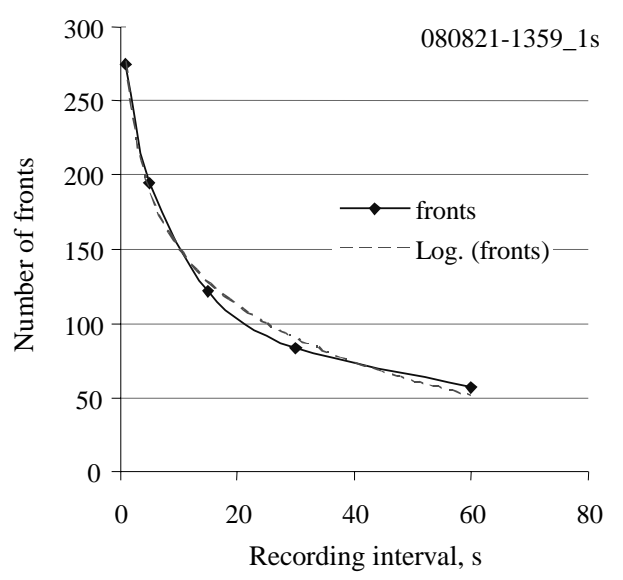

Fig. 8. Dependence of recorded fronts depending on the sampling interval.

\section{CONCLUSIONS}

1. Massive measurements in the BSRN, recording one-minute average values, cannot present accompanying fast changes of solar radiation in the case of cumulus humilis.

2. In these conditions frequency of clouds is from three to five times larger than registered in the BSRN.

3. From the point of view of dynamics, the registration of one-minute instant values should be preferred.

Both criterions of the comparison, the standard deviation and the registered number of the fronts per time unit, confirm these conclusions.

\section{ACKNOWLEDGEMENT}

Authors are thankful to the Estonian Science Foundation, who has supported this investigation (grant No. 7332).

\section{REFERENCES}

1. Tomson, T. Fast dynamic processes of solar radiation. Solar Energy, 2010, 84, 318-323.

2. Gansler, A., Beckman, W. A. and Klein, S. A. Investigation of minute solar radiation data. Solar Energy, 1995, 55, 21-27.

3. Soubdhan, T. and Feuillard, T. Preliminary study of one minute solar radiation measurements under tropical climate. In Proc. ISES 2005 Solar World Congress. CD-ROM, paper 1511.

4. Tomson, T. and Tamm, G. Short-term variability of solar radiation. Solar Energy, 2006, 80, 600606.

5. Tovar, J., Alados-Arboledas, L. and Olmo, F. J. One-minute global irradiance probability density distributions conditioned to the optical air mass. Solar Energy, 1998, 62, 387-393. 
6. Tomson, T., Russak, V. and Kallis, A. Dynamic behavior of solar radiation. In Modeling Solar Radiation at the Earth's Surface (Badescu, V., ed.). Springer Verlag, Berlin-Heidelberg, 2008, 257-281.

\section{Päikese kiiritustiheduse kiired muutused}

\section{Teolan Tomson ja Maire Hansen}

On võrreldud päikese kiiritustiheduse sekundilise sampimisintervalliga tehtud mõõtmisi selle traditsiooniliste mõõtmistega. Kiiritustiheduse dünaamilisi omadusi on võimalik kirjeldada kolme iseloomuliku parameetriga. Nendeks on mõõdetud andmestiku (libisev) standardhälve, kiiritustiheduse inkrementide jaotusseadus ja kiiritustiheduse muutuste sagedus (kiiritustiheduse frontide arv ajaühikus). Mõistagi on viimane juhuslik suurus. On näidatud, et kõrge sagedusega cumulus humilis pilvede korral läheb traditsioonilise kiiritustiheduse üheminutiliste keskväärtuste registreerimisega oluline osa dünaamilist infot kaduma. 